\title{
Saçlı meşe (Quercus cerris L.)'nin fidan kalitesi üzerinde tüp boyutu ve kökçük kırmanın etkisi
}

\author{
Ayşe Deligöz ${ }^{\mathrm{a}, *}$ (D), Osman Gençera (i)
}

\begin{abstract}
Özet: Bu çalışma, ülkemizdeki kurak ve yarı kurak bölgelerde yapılan ağaçlandırma çalışmalarında tercih edilen türler arasında yer alan saçlı meşede (Quercus cerris L.) tüp boyutu ve kökçük kırmanın fidan kalitesi üzerindeki etkisini araștırmak amacıyla gerçekleştirilmiştir. Çalışmada dört farklı tüp boyutunda $(11 \times 22 \mathrm{~cm}, 12 \times 25 \mathrm{~cm}, 14 \times 35 \mathrm{~cm}$ ve $18 \times 30 \mathrm{~cm})$ kökçük kırma işlemleri (kontrol ve kökçük kırma) ile yetiştirilen 1+0 yaşlı fidanlarda bazı morfolojik (kök boğazı çapı, fidan boyu, gövde ve kök kuru ağırlı̆̆ı, gövde:kök oranı, ana kök sayısı, yan kök sayısı, gürbüzlük indisi vb.) ve fizyolojik (gövde ve kök toplam karbonhidrat içeriği, kök gelişme potansiyeli) fidan özellikleri belirlenmiştir. Elde edilen sonuçlara göre, tüp boyutu ana kök sayısı ve gövde toplam karbonhidrat içeriği dışında ölçümü yapılan diğer fidan kalite özellikleri üzerinde etkili bulunmuştur. Kökçük kırma işlemi ise gövde:kök oranı, çapı $1 \mathrm{~mm}$ 'den büyük yan kök sayısı, gürbüzlük indisi, gövde toplam karbonhidrat içeriği ve kök gelişme potansiyeli üzerinde etkisiz bulunmuştur. Kökçük kırma işlemi uygulanan fidanlarda tüp boyutu arttıkça kök boğazı çapı, fidan boyu, gövde kuru ağırlığı, ana, yan ve toplam kök kuru ağırlığı arttırmıştır. Kökçük kırma işlemi ana kök sayısını arttırmış, kök yüzdesi ve kök toplam karbonhidrat içeriğini düşürmüştür. En büyük tüp boyutunda daha kalın çaplı, boylu, daha ağır, yan dal sayısı ve yan kök sayısı daha yüksek fidanlar üretilmiştir.
\end{abstract}

Anahtar kelimeler Saçlı meşe, Fidan kalitesi, Fidan boyu, Kök boğazı çapı, Kök gelişme potansiyeli, Morfoloji

\section{Effects of container size and radicle pruning on seedling quality of Turkey oak (Quercus cerris L.)}

\begin{abstract}
This aim of this study was to assess the effect of container size and radicle pruning at the time sowing on seedling quality in Turkey oak (Quercus cerris L.), which are among the preferred species in afforestation studies in arid and semi-arid regions in our country. In the study, some morphological (root collar diameter, height, shoot and root dry weight, shoot:root ratio, number of main roots, number of lateral roots, sturdiness ratio etc.) and physiological (shoot and root total carbohydrate content, root growing potential) characteristics were determined in $1+0$ year old seedling grown in four different polybag sizes $(11 \times 22 \mathrm{~cm}$, $12 \times 25 \mathrm{~cm}, 14 \times 35 \mathrm{~cm}$ and $18 \times 30 \mathrm{~cm}$ ) with or without radicle pruning. According to the results, the container size had significant effect on the seedling quality, except for the number of main roots and stem total carbohydrate content. The radicle pruning did not affect the shoot: root ratio, the number of lateral roots greater than $1 \mathrm{~mm}$ in diameter, the sturdiness quotient (seedling height:diameter ratio), the stem total carbohydrate content and the root growing potential. The root collar diameter, height, shoot dry weight, main, lateral and total root dry weight increased with increasing polybags size with radicle pruning. Radicle pruning increased number of main roots, but the root percentage and root total carbohydrate content were decreased. Seedling grown in the largest polybags had greater diameter, taller, heavier, higher the number of lateral branches and the number of lateral roots.

Keywords: Turkey oak, Seedling quality, Seedling height, Root collar diameter, Root growth potential, Morphology
\end{abstract}

\section{Giriş}

İklim değişikliği, çölleşme, ormansızlaşma, biyolojik çeşitlilik kaybı, kuraklık gibi çevre problemleri her geçen gün insan yaşamını belirgin bir şekilde etkilemektedir. Bu problemlerin çoğunun temelinde ormanların yok olması yatmaktadır. Ülkemiz coğrafi konumu itibari ile iklim değişikliğinden en çok etkilenecek ülkeler arasında yer almaktadır. Fosil yakıtların yanması, arazi kullanımındaki değişiklikler, ormansızlaştırma ve sanayi süreçleri gibi insan etkinlikleriyle atmosfere salınan sera gazı birikimlerindeki hızlı artışın doğal sera etkisini kuvvetlendirmesi sonucunda yerküre sıcaklığındaki artış ve bunun sonucu olarak ortaya çıkan etkiler iklim değişikliği olarak tanımlanmaktadır (İğci ve Çobanoğlu, 2019; Türkeş, 2020). Küresel iklim değişikliği ile meydana gelen isınma; ormanlara ve orman yangınlarına etki etmektedir. Diğer taraftan ormanların azalması nedeniyle karbondioksit emiliminin yeterince yerine getirilememesi ise 1sınmayı tetiklemektedir (Batan ve Toprak, 2020). Bu nedenle ormanlık alanların korunması amacıyla çeşitli nedenlerle yok edilen orman alanlarının özellikle kurak-yarıkurak bölgelerdeki bozuk yapıların ağaçlandırma ve diğer imar-ihya çalışmaları ile tekrar verimli hale getirilmesi, ormanların çok yönlü fonksiyonlarının geri kazanılması açısından oldukça önemlidir.

\footnotetext{
$\bowtie$ a Isparta Uygulamalı Bilimler Üniversitesi Orman Fakültesi, Orman Mühendisliği Bölümü Isparta, Türkiye

@ * Corresponding author (İletişim yazarı): aysedeligoz@ isparta.edu.tr

$\checkmark \quad$ Received (Geliş tarihi): 24.04.2021, Accepted (Kabul tarihi): 26.07.2021
}

Citation (Atıf): Deligöz, A., Gençer, O., 2021. Saçlı meşe (Quercus cerris L.)'nin fidan kalitesi üzerinde tüp boyutu ve kökçük kırmanın etkisi. Turkish Journal of Forestry, 22(3): 211-217. DOI: $\underline{10.18182 / \text { tjf.927068 }}$ 
Son yıllarda gerek Avrupa'da gerekse Türkiye'de doğal geniş yapraklı türlerle yapılan ağaçlandırma çalışmalarının önem kazandığg belirtilmektedir (Ayan vd., 2020). Toprağın korunması ve yararlanabilir orman kaynağını arttırmak amaciyla Orman Genel Müdürlüğ̈̈nce yapılan ağaçlandırma çalışmalarının çoğunluğu ülkemizin toprak ve iklim koşulları bakımından en zor şartları taşıyan yarı kurak sahalarda yapılmaktadır (Tüfekçi vd., 2016). Kurak ve yarı kurak soğuk bölgelerden İç Anadolu'daki uygun ekolojik koşullarda ve Güneydoğu Anadolu Bölgesi'nin kuzeyi ve güneyindeki uygun ekolojik koşullarda kullanılabilecek türler arasında saçlı meşe türü de gösterilmiştir (Boydak ve Çalışkan, 2014). Saçlı meşe 25-30 metreye kadar boy, 1-1.2 metre çap yapabilen geniş tepeli bir ağaçtır. Ülkemizin Kuzeydoğu ve Doğu Anadolu bölgeleri dışındaki diğer bölgelerinde geniş bir yayılışa sahiptir. Deniz seviyesinden 1500-1900 m yüksekliklere kadar çıkabilir (Yaltırık, 1984, Anşin ve Özkan, 1993).

Kurak ve yarı kurak alanlardaki başarı için öncelikle yörenin ekolojik koşullarına uygun tür ve orijin seçimi, uygun bir fidanlık tekniği ile bu alanlar için kaliteli fidan üretimi, uygun arazi hazırlığı, kaliteli fidanların dikimi ve bakımı esas olmalıdır. Kaplı fidan kullanımı bu sahalardaki başarı açısından oldukça önemlidir (Alptekin ve İmal, 2010). Kaplı fidan üretiminde yetiştirme ortamı, kap özellikleri ve boyutu oldukça önemlidir. Uygulamada farklı boyutlarda kaplı fidan kullanımı yaygındır. Bununla birlikte uygun kap boyutları, tipleri, nitelikleri ve başarı durumu hakkında yapılmış çalışma sayısı oldukça kısıtlıdır.

Kök büyümesi bir kabın ortam hacmiyle sınırlıdır. Kap özellikleri, kök gelişsimini ve dolayısıyla da fidan gelişimini etkilemektedir. Kaplarda yetiştirilen fidanlar kök gelişimini ve işlevini etkileyebilir ve bunun sonucu olarak da kök morfolojisini değiştirebilir (Mathers vd., 2007). Değişen kök morfolojisi küçük boyutlu kaplarda daha belirgin hale gelebilir. Ayrıca, küçük hacimli kaplar ile kök sistemi sınırlandırıldığında, kök ve gövde arasındaki hassas denge bozulabilir (NeSmith ve Duval, 1998). Fizyolojik işlevlerini yerine getirebilen iyi bir kök sistemi, fidanların yaşaması ve gelişimi için gereklidir. Bir kök sisteminin oluşumu çimlenme aşaması ile başlar ve fidanlık uygulamaları kök gelişimini büyük ölçüde etkileyebilir (Hahn ve Hutchison, 1978). Yeni dikilen fidanların dikim stresinin üstesinden gelebilme yeteneği, kök sistem büyüklüğü ve dağılımından etkilenmektedir (Sutton, 1980; Grossnickle, 2005). İyi bir kök sistemine sahip kaliteli fidanlar, dikim sonrası hayatta kalma ve gelişimi kolaylaştırır (Chouial ve Benamirouche, 2016). Tüm bu hususlar çerçevesinde bu çalışmanın amacı ekim sırasındaki kökçük kırmanın ve tüp boyutunun saçlı meşe fidanlarında özellikle kök gelişimi olmak üzere fidanların bazı morfolojik ve fizyolojik özellikleri üzerindeki etkisini ortaya koymaktır.

\section{Materyal ve yöntem}

\subsection{Tohum temini, deneme deseni ve fidan üretimi}

Araştırma materyali tohumlar, Isparta Orman Bölge Müdürlüğü, Sütçüler Orman İşletme Müdürlüğü, Sipahiler Orman İşletme Şefliği sınırları içinde yer alan $1280 \mathrm{~m}$ yükseltili saçlı meşe meşceresinden ( $32^{\circ} 26^{\prime} 46^{\prime \prime} \mathrm{K}, 41^{\circ} 68^{\prime}$ 95" D) 2018 yılının kasım ayında toplanmıştır. Oda koşullarında 24 saat suda bekletilen tohumlardan boş ve çürük olanları ayıklanarak kalan tohumlar polietilen torbalarda $+4^{\circ} \mathrm{C}$ 'deki soğuk hava deposunda ekim tarihine kadar saklanmıştır. Ekim çalışmaları 2019 yılı mart ayında ISUBU Orman Fakültesi Araştırma ve Uygulama Fidanlığı'nda gerçekleştirilmiştir. Yetiştirme ortamı olarak turba-perlit (3:1) karışımı içeren dört farklı boyuttaki (11x22 $\mathrm{cm}, 12 \times 25 \mathrm{~cm}, 14 \times 35 \mathrm{~cm}$ ve $18 \times 30 \mathrm{~cm}$ ) polietilen tüplere tohumlar ekilmiştir. Kontrol ve kökçük kırma olmak üzere iki işlem 4 farklı tüp boyutunda üç tekerrürlü olarak uygulanmıştır. Her tüpe 1'er adet tohum ekilmiştir. Kökçük kırma işleminde soğuk saklama süresince çimlenen tohumların kökçükleri dipten $1 \mathrm{~cm}$ mesafeden bağ makası ile kesilmiştir. Kontrol işleminde ise kökçük boyları en fazla $1 \mathrm{~cm}$ olan tohumlar kullanılarak, herhangi bir kesim işlemi uygulanmamıştır. Tohumlar, çimlenmeler tamamlanıncaya kadar geçen sürede düzenli aralıklarla, çimlenmeler tamamlandıktan sonra yağışsız günlerde hava sıcaklığına bağlı olarak 3-4 günde bir sulanmıştır. Yaz boyunca sürdürülen sulamalar sonbahar yağışlarının başlaması ile tamamlanmıştır. Yabancı ot gelişimine bağlı olarak belli aralıklarla ot alımı gerçekleştirilmiştir.

\subsection{Morfolojik ölçümler}

2020 yılı şubat ayı sonunda dört farklı tüp boyutunda kontrol ve kökçük kırma işlemi ile yetiştirilen saçlı meşe fidanları tüplerinden sökülmüştür. Fidan morfolojik özelliklerinden kök boğaz çapı, fidan boyu, gövde ve kök kuru ağırlığı, yan dal sayısı, kök sayısı (ana kök sayısı, yan kök sayısı, çap1 $1 \mathrm{~mm}$ ' den büyük yan kök sayıs1), gövde/kök oranı, Dickson kalite indeksi, gürbüzlük indisi ve kök yüzdesi belirlenmiştir.

\subsection{Fizyolojik ölçümler}

Fidan fizyolojik özelliklerinden toplam karbonhidrat içeriği ve kök gelişme potansiyeli tespit edilmiştir. Kök gelişme potansiyelinin tespiti için her bir işlemden toplam 18 fidan (6 x 3 yineleme) kullanılmıştır. Her bir fidanın kök sistemi üzerinde yeni oluşmuş beyaz kök uçları bulunuyorsa bu yeni kökler makas yardımıyla uzaklaştırılmıştır. Fidanlar humus ve perlit karışımı (3:1 hacim olarak) içeren enso kaplara dikilmiş ve kontrollü koşullarda $\left(19 / 23^{\circ} \mathrm{C}, \%\right.$ 55-80 bağıl nem, 16 saat fotoperiod) bitki büyütme odasına yerleştirilmiştir. Düzenli sulama yapılarak 30. gün sonunda fidanlar sökülmüştür. Sökümün ardından yeni oluşan $1 \mathrm{~cm}$ 'den uzun beyaz kök uçları sayılarak kök gelişme potansiyeli belirlenmiştir. Karbonhidrat analizi için kullanılan fidanların gövde ve kök örnekleri $65{ }^{\circ} \mathrm{C}$ 'de 48 saat kurutulmuş, sonrasında kahve öğütücü yardımıyla öğütülmüştür. Toplam karbonhidrat içeriği (serbest şekerler) $\left(\mathrm{mg} \mathrm{g}^{1}\right)$ gövde ve kök örneklerinde Dubois vd. (1956) göre fenol sülfürik asit yöntemine göre belirlenmiştir. Ayrıca fidanların TSE standartlarına göre kalite değerlendirmelerinde TS 5624/Mart 1988 no'lu Yapraklı Orman Ağacı Fidanları standardı esas alınmıştır.

\subsection{Verilerin değerlendirilmesi}

Elde edilen veriler SPSS 20.0 istatistik paket programı kullanılarak değerlendirilmiştir. Tüp boyutu ve kök kırmanın fidan morfolojik ve fizyolojik özellikleri üzerindeki etkisini belirleyebilmek amacıyla varyans analizi uygulanmıştır. Varyans analizi sonucunda istatistiksel anlamda önemli farklılıkların bulunması durumunda Duncan 
testi uygulanmıştır. Gerekli verilerde analiz öncesi dönüşümler uygulanmıştır.

\section{Bulgular}

Tüp boyutu ana kök sayısı dışında, kökçük kırma işlemi ise gövde:kök oranı, 1 mm'den büyük yan kök sayısı ve gürbüzlük indisi dışındaki diğer ölçümü yapılan fidan morfolojik özellikleri üzerinde istatistiksel anlamda etkili bulunmuştur (Çizelge 1). Tüp boyutu x kökçük kırma etkileşimi ise yan kök sayısı dışında önemsiz bulunmuştur (Çizelge 1).

Tüp boyutu ve kökçük kırma işlemlerinin fidanların morfolojik özellikleri üzerindeki etkisi incelendiğinde (Çizelge 2); Kök boğazı çapı $2.94 \mathrm{~mm}$ ile $5.67 \mathrm{~mm}$ arasında, fidan boyu $7.15 \mathrm{~cm}$ ile $16.23 \mathrm{~cm}$ arasında, gövde kuru ağırlığ $0.17 \mathrm{~g}$ ile $1.16 \mathrm{~g}$ arasında, yan kök ağırlığ $0.11 \mathrm{~g}$ ile $0.55 \mathrm{~g}$ arasında, ana kök ağırlığı $1.03 \mathrm{~g}$ ile $4.94 \mathrm{~g}$ arasında ve toplam kök kuru ağırlığı $1.14 \mathrm{~g}$ ile $5.49 \mathrm{~g}$ arasında değişmektedir. En büyük tüp boyutunda $(18 \times 30 \mathrm{~cm})$ en yüksek kök boğazı çapı, fidan boyu, gövde kuru ağırlığı ve yandal sayıs1, $11 \times 22 \mathrm{~cm}$ tüp boyutu ile $12 \times 25 \mathrm{~cm}$ tüp boyutunda ise en düşük kök boğazı çapı elde edilmiştir. En kısa boylu ve gövde kuru ağırlığı bakımından daha düşük fidanlar ise $12 \times 25 \mathrm{~cm}$ tüp boyutunda üretilmiştir. Kontrol fidanları ile karşılaştırıldığında kökçük kırma işleminin yapıldığı tohumlardan elde edilen fidanlarda kök boğazı çapı, fidan boyu, gövde kuru ağırlığı, yandal sayısı, ana kök, yan kök ve toplam kök kuru ağırlığı değerleri daha yüksektir. Tüp boyutu arttıkça kök kuru ağırlıkların da arttığ 1 belirlenmiştir. Gövde: kök oranı bakımından en küçük tüp boyutunda en büyük gövde:kök oranı elde edilirken, diğer tüp boyutları daha küçük gövde:kök oranları ile kendi içlerinde benzer bulunmuştur (Çizelge 2).

Kökçük kırma işlemi ana kök sayısını arttırmıştır (Çizelge 2). Kontrol işleminde elde edilen tüm fidanlarda ana kök sayısı 1 adet iken, kökçük kırma işlemlerinde en fazla 6 adet olarak belirlenmiştir. Yan kök sayısı ve 1 mm'den büyük yan kök sayısı en büyük tüp boyutunda $(18 \times 30 \mathrm{~cm})$ daha fazladır. Kök yüzdesi bakımından en iyi sonucu veren grupta $12 \times 25 \mathrm{~cm}, 14 \times 35 \mathrm{~cm}$ ve $18 \times 30 \mathrm{~cm}$ tüp boyutları yer almakta ve bu üç tüp boyutu benzerdir. En kaliteli fidanlar Gürbüzlük indisine göre $12 \times 25 \mathrm{~cm}$ ve $14 \times 35$ cm tüp boyutlarında elde edilirken, Dickson kalite indeksine göre en büyük tüp boyutunda $(18 \times 30 \mathrm{~cm})$ belirlenmiştir (Çizelge 2).

Tüp boyutu ve kökçük kırma işlemlerinin fidanların fizyolojik özellikleri üzerindeki etkisi incelendiğinde ise (Çizelge 3); Köklerde belirlenen en yüksek toplam karbonhidrat içeriği en büyük tüp boyutunda $(18 \times 30 \mathrm{~cm})$ kontrol işleminde elde edilmiştir. Diğer tüp boyutlarının toplam karbonhidrat içeriği benzerdir (Çizelge 3). Kökçük kırma işlemleri bazında değerlendirme yapıldığında ise kontrol fidanlarında daha yüksek kök toplam karbonhidrat içeriği tespit edilmiştir. En büyük tüp boyutunda yetiştirilen fidanların kök gelişme potansiyeli en yüksektir. Kök gelişme potansiyeli en az olan fidanlar ise $11 \times 22 \mathrm{~cm}, 12 \times 25$ $\mathrm{cm}$ ve $14 \times 35 \mathrm{~cm}$ tüp boyutlarında elde edilmiştir. Kökçük kırma işlemi kök gelişme potansiyeli üzerinde etkili bulunmamıştır.

TSE tarafindan Mart 1988'de geniş yapraklı ağaç fidanı standardına göre tüplü saçlı meşe fidanları 2 kalite sınıfına ayrılmıştır. $\mathrm{Bu}$ sınıflandırmaya göre I. sınıf tüplü meşe fidanların çapının en az $5 \mathrm{~mm}$ ve boyunun en az $40 \mathrm{~cm}$ olması gerekirken, II. sınıf fidanların çapının en az $4 \mathrm{~mm}$ ve boyunun en az $30 \mathrm{~cm}$ olması gerekmektedir (Çizelge 4). TS5624/Mart 1988 tarihli standarda göre yapılan değerlendirmede, saçlı meşe fidanlarının kalite sınıflarına dağıtımı yapılmıştır. Buna göre, tüp boyutu ve kökçük kırma işlemlerinde elde edilen tüm fidanların standart dışı kaldığı tespit edilmiştir (Çizelge 4).

Çizelge 1. Fidan morfolojik ve fizyolojik özelliklerine ait varyans analizi sonuçları

\begin{tabular}{|c|c|c|c|c|c|c|}
\hline \multirow[b]{2}{*}{ Özellikler } & \multicolumn{2}{|c|}{ Tüp boyutu (A) } & \multicolumn{2}{|c|}{ Kökçük kırma (B) } & \multicolumn{2}{|c|}{$\mathrm{A} \times \mathrm{B}$} \\
\hline & F değeri & P değeri & F değeri & $\mathrm{P}$ değeri & F değeri & P değeri \\
\hline Kök boğazı çapı (mm) & 65.74 & $<0.001$ & 49.35 & $<0.001$ & 1.62 & .186 \\
\hline Fidan boyu $(\mathrm{cm})$ & 35.40 & $<0.001$ & 13.28 & $<0.001$ & 1.75 & .157 \\
\hline Gövde kuru ağırlığı (g) & 47.46 & $<0.001$ & 29.12 & $<0.001$ & 1.03 & .380 \\
\hline Yan kök ağırlı̆̆ı (g) & 19.56 & $<0.001$ & 5.89 & $<0.05$ & 2.46 & .065 \\
\hline Ana kök ağırlığ $1(\mathrm{~g})$ & 60.29 & $<0.001$ & 10.43 & $<0.01$ & .61 & .607 \\
\hline Toplam kök ağırlığı $(\mathrm{g})$ & 60.53 & $<0.001$ & 11.15 & $<0.01$ & .63 & .598 \\
\hline Gövde:kök oranı & 8.39 & $<0.001$ & 1.27 & .262 & .60 & .616 \\
\hline Yandal sayısı (adet) & 8.14 & $<0.001$ & 7.90 & $<0.01$ & .04 & .991 \\
\hline Ana kök sayısı (adet) & 1.14 & .336 & 583.69 & $<0.001$ & 1.14 & .336 \\
\hline Yan kök sayısı (adet) & 4.28 & $<0.01$ & 6.93 & $<0.01$ & 3.24 & $<0.05$ \\
\hline Yan kök sayısı>1 mm (adet) & 8.29 & $<0.001$ & .09 & .766 & .13 & .941 \\
\hline Kök yüzdesi (\%) & 12.36 & $<0.001$ & 4.209 & $<0.05$ & .35 & .789 \\
\hline Gürbüzlük indisi & 7.26 & $<0.001$ & 0.000 & .987 & 1.42 & .238 \\
\hline Dickson kalite indeksi & 36.80 & $<0.001$ & 6.41 & $<0.05$ & 2.08 & .105 \\
\hline Gövde karbonhidrat içeriği $\left(\mathrm{mg} \mathrm{g}^{-1}\right)$ & 1.66 & .215 & .007 & .933 & .23 & .873 \\
\hline Kök karbonhidrat içeriği $\left(\mathrm{mg} \mathrm{g}^{-1}\right)$ & 7.63 & $<0.01$ & 7.83 & $<0.05$ & 4.65 & $<0.05$ \\
\hline Kök gelişme potansiyeli (adet) & 3.64 & $<0.05$ & 3.55 & .063 & .48 & .696 \\
\hline
\end{tabular}


Çizelge 2. Tüp boyutu ve kökçük kırma işlemlerinin 1+0 yaşlı saçlı meşe fidanların morfolojik özellikleri üzerindeki etkisi

\begin{tabular}{|c|c|c|c|c|c|c|}
\hline \multirow{2}{*}{ Özellik } & \multirow{2}{*}{ İşlem } & \multicolumn{4}{|c|}{ Tüp boyutu $(\mathrm{cm})$} & \multirow{2}{*}{ Ortalama* } \\
\hline & & $11 \times 22$ & $12 \times 25$ & $14 \times 35$ & $18 \times 30$ & \\
\hline \multirow{3}{*}{ Kök boğazı çapı (mm) } & Kontrol & 3.03 & 2.94 & 3.36 & 4.55 & $3.47 b$ \\
\hline & Kökçük kırma & 3.64 & 3.43 & 4.16 & 5.67 & $4.23 a$ \\
\hline & Ortalama** & $3.34 c$ & $3.19 c$ & $3.76 b$ & $5.11 a$ & \\
\hline \multirow{3}{*}{ Fidan boyu (cm) } & Kontrol & 8.60 & 7.15 & 8.40 & 12.74 & $9.22 b$ \\
\hline & Kökçük kırma & 10.75 & 7.33 & 10.10 & 16.23 & $11.10 a$ \\
\hline & Ortalama ${ }^{* *}$ & $9.68 b$ & $7.24 c$ & $9.25 b$ & $14.49 a$ & \\
\hline \multirow{3}{*}{ Gövde kuru ağırlığı (g) } & Kontrol & 0.30 & 0.17 & 0.38 & 0.80 & $0.41 b$ \\
\hline & Kökçük kırma & 0.53 & 0.30 & 0.66 & 1.16 & $0.66 a$ \\
\hline & Ortalama ${ }^{* *}$ & $0.41 b$ & $0.24 c$ & $0.52 b$ & $0.98 a$ & \\
\hline \multirow{3}{*}{ Yan kök ağırlı̆̆ı (g) } & Kontrol & 0.11 & 0.18 & 0.32 & 0.36 & $0.24 b$ \\
\hline & Kökçük kırma & 0.13 & 0.31 & 0.30 & 0.55 & $0.32 a$ \\
\hline & Ortalama & $0.12 c$ & $0.24 b$ & $0.31 b$ & $0.46 a$ & \\
\hline \multirow{3}{*}{ Ana kök ağırlı̆̆ı (g) } & Kontrol & 1.03 & 1.12 & 2.14 & 3.99 & $2.07 b$ \\
\hline & Kökçük kırma & 1.42 & 1.47 & 2.98 & 4.94 & $2.70 a$ \\
\hline & Ortalama $^{* *}$ & $1.23 c$ & $1.29 c$ & $2.56 b$ & $4.47 a$ & \\
\hline \multirow{3}{*}{ Toplam kök ağırlığı (g) } & Kontrol & 1.14 & 1.30 & 2.47 & 4.35 & $2.31 b$ \\
\hline & Kökçük kırma & 1.55 & 1.77 & 3.27 & 5.49 & $3.02 a$ \\
\hline & Ortalama $^{* *}$ & $1.34 c$ & $1.54 c$ & $2.87 b$ & $4.92 a$ & \\
\hline \multirow{3}{*}{ Gövde/kök oranı } & Kontrol & 0.29 & 0.17 & 0.23 & 0.20 & $0.22 a$ \\
\hline & Kökçük kırma & 0.36 & 0.20 & 0.21 & 0.22 & $0.25 a$ \\
\hline & Ortalama & $0.33 a$ & $0.19 b$ & $0.22 b$ & $0.21 b$ & \\
\hline \multirow{3}{*}{ Yandal sayısı (adet) } & Kontrol & 0.43 & 0.13 & 0.10 & 0.83 & $0.38 b$ \\
\hline & Kökçük kırma & 0.83 & 0.43 & 0.43 & 1.43 & $0.78 a$ \\
\hline & Ortalama ${ }^{* *}$ & $0.63 b$ & $0.28 b$ & $0.27 b$ & $1.13 a$ & \\
\hline \multirow{3}{*}{ Kök yüzdesi (\%) } & Kontrol & 78.28 & 85.82 & 83.56 & 83.83 & $82.87 a$ \\
\hline & Kökçük kırma & 74.18 & 83.89 & 82.80 & 82.44 & $80.82 b$ \\
\hline & Ortalama ${ }^{* *}$ & $76.23 b$ & $84.86 a$ & $83.18 a$ & $83.14 a$ & \\
\hline \multirow{3}{*}{ Ana kök sayısı (adet) } & Kontrol & 1.00 & 1.00 & 1.00 & 1.00 & $1.00 a$ \\
\hline & Kökçük kırma & 3.00 & 2.83 & 3.20 & 3.30 & $3.08 b$ \\
\hline & Ortalama ${ }^{* *}$ & $2.00 a$ & $1.92 a$ & $2.10 a$ & $2.15 a$ & \\
\hline \multirow{3}{*}{ Yan kök sayısı (adet) } & Kontrol & 11.47 & 13.10 & 10.70 & 12.07 & $11.83 b$ \\
\hline & Kökçük kırma & 10.30 & 12.43 & 13.93 & 20.47 & $14.28 a$ \\
\hline & Ortalama & $10.88 b$ & $12.77 b$ & $12.32 b$ & $16.27 a$ & \\
\hline \multirow{3}{*}{ Yan kök sayısı>1 mm (adet) } & Kontrol & 0.13 & 0.40 & 0.33 & 1.03 & $0.48 a$ \\
\hline & Kökçük kırma & 0.20 & 0.37 & 0.50 & 0.93 & $0.50 a$ \\
\hline & Ortalama ${ }^{* *}$ & $0.17 b$ & $0.38 b$ & $0.42 b$ & $0.98 a$ & \\
\hline \multirow{3}{*}{ Gürbüzlük indisi } & Kontrol & 28.21 & 24.81 & 25.23 & 27.11 & $26.34 a$ \\
\hline & Kökçük kırma & 30.27 & 21.67 & 24.41 & 28.94 & $26.32 a$ \\
\hline & Ortalama ${ }^{* *}$ & $29.24 a$ & $23.24 b$ & $24.82 b$ & $28.02 a$ & \\
\hline \multirow{3}{*}{ Dickson kalite indeksi } & Kontrol & 0.05 & 0.10 & 0.17 & 0.26 & $0.14 a$ \\
\hline & Kökçük kırma & 0.07 & 0.06 & 0.12 & 0.20 & $0.11 b$ \\
\hline & Ortalama $^{* *}$ & $0.06 c$ & $0.08 c$ & $0.14 b$ & $0.23 a$ & \\
\hline
\end{tabular}

${ }^{*}$ Sütun üzerinde farklı harfi içeren ortalamalar arasında anlamlı fark bulunmaktadır $(\mathrm{p}<0.05)$

${ }^{* *}$ Satır üzerinde farklı harfi içeren ortalamalar arasında anlamlı fark bulunmaktadır $(\mathrm{p}<0.05)$

Çizelge 3. Tüp boyutu ve kökçük kırma işlemlerinin $1+0$ yaşlı saçlı meşe fidanların fizyolojik özellikleri üzerindeki etkisi

\begin{tabular}{|c|c|c|c|c|c|c|}
\hline \multirow{2}{*}{ Özellik } & \multirow{2}{*}{ İşlem } & \multicolumn{4}{|c|}{ Tüp boyutu $(\mathrm{cm})$} & \multirow[t]{2}{*}{ Ortalama } \\
\hline & & $11 \times 22$ & $12 \times 25$ & $14 \times 35$ & $18 \times 30$ & \\
\hline \multirow{3}{*}{$\begin{array}{l}\text { Gövde toplam karbonhidrat içeriği } \\
\left(\mathrm{mg} \mathrm{g}^{-1}\right)\end{array}$} & Kontrol & 36.36 & 39.04 & 37.37 & 34.62 & $36.85 a$ \\
\hline & Kökçük kırma & 34.27 & 41.72 & 37.88 & 34.23 & $37.02 a$ \\
\hline & Ortalama $^{* *}$ & $35.32 a$ & $40.38 a$ & $37.62 a$ & $34.42 a$ & \\
\hline \multirow{3}{*}{$\begin{array}{l}\text { Kök toplam karbonhidrat içeriği } \\
\left(\mathrm{mg} \mathrm{g}^{-1}\right)\end{array}$} & Kontrol & 22.85 & 21.42 & 20.06 & 27.51 & $22.96 a$ \\
\hline & Kökçük kırma & 14.66 & 16.14 & 23.90 & 23.82 & $19.63 b$ \\
\hline & Ortalama ${ }^{* *}$ & $18.76 b$ & $18.78 b$ & $21.98 b$ & $25.67 a$ & \\
\hline \multirow{3}{*}{ Kök gelişme potansiyeli (adet) } & Kontrol & 0.58 & 1.75 & 1.25 & 2.83 & $1.60 a$ \\
\hline & Kökçük kırma & 0.42 & 0.33 & 0.67 & 2.08 & $0.88 a$ \\
\hline & Ortalama $^{* *}$ & $0.50 b$ & $1.04 b$ & $0.96 b$ & $2.46 a$ & \\
\hline
\end{tabular}

${ }^{*}$ Sütun üzerinde farklı harfi içeren ortalamalar arasında anlamlı fark bulunmaktadır $(\mathrm{p}<0.05)$

${ }^{* *}$ Satır üzerinde farklı harfi içeren ortalamalar arasında anlamlı fark bulunmaktadır $(\mathrm{p}<0.05)$ 
Çizelge 4. TS5624/Mart 1988 tarihli fidan kalite sınıflandırmasına göre fidan dağılımı

\begin{tabular}{|c|c|c|c|c|c|c|}
\hline \multirow[b]{2}{*}{ Tüp boyutu } & \multirow[b]{2}{*}{ Kökçük kırma } & \multirow[b]{2}{*}{ Fidan sayısı } & \multicolumn{2}{|c|}{ Kalite sınıfları $(\%)$} & \multirow[b]{2}{*}{$\begin{array}{c}\text { Toplam } \\
\text { ( I+II) }\end{array}$} & \multirow[b]{2}{*}{ Iskarta } \\
\hline & & & $\begin{array}{c}\text { I } \\
\text { Boy: En az } 40 \mathrm{~cm} \\
\text { Çap: En az } 5 \mathrm{~mm}\end{array}$ & $\begin{array}{c}\text { II } \\
\text { Boy: En az } 30 \mathrm{~cm} \\
\text { Çap: En az } 4 \mathrm{~mm}\end{array}$ & & \\
\hline \multirow{2}{*}{$11 \times 22 \mathrm{~cm}$} & Kontrol & 30 & 0.0 & 0.0 & 0.0 & 100 \\
\hline & Kökçük kırma & 30 & 0.0 & 0.0 & 0.0 & 100 \\
\hline \multirow{2}{*}{$12 \times 25 \mathrm{~cm}$} & Kontrol & 30 & 0.0 & 0.0 & 0.0 & 100 \\
\hline & Kökçük kırma & 30 & 0.0 & 0.0 & 0.0 & 100 \\
\hline \multirow{2}{*}{$14 \times 35 \mathrm{~cm}$} & Kontrol & 30 & 0.0 & 0.0 & 0.0 & 100 \\
\hline & Kökçük kırma & 30 & 0.0 & 0.0 & 0.0 & 100 \\
\hline \multirow{2}{*}{$18 \times 30 \mathrm{~cm}$} & Kontrol & 30 & 0.0 & 0.0 & 0.0 & 100 \\
\hline & Kökçük kırma & 30 & 0.0 & 0.0 & 0.0 & 100 \\
\hline
\end{tabular}

\section{Tartışma ve sonuç}

Kaplı fidan üretiminde kap boyutu ve kapların tasarım özellikleri fidan kalitesinin önemli belirleyicileridir (Landis vd., 1990). Özellikle hacmi, bir kabın en belirgin ve önemli özelliklerinden birisidir. Optimum kap boyutu, tür, yetiştirme sıklığg, çevresel koşullar ve büyüme mevsiminin uzunluğu gibi birçok faktöre bağlı olarak değişir. Saçlı meşe fidanlarında tüp boyutunun ve kökçük kırmanın etkisinin araştırıldığ 1 bu çalışmada, önemli fidan kalite kriterleri arasında yer alan kök boğazı çapının ve fidan boyunun hem tüp boyutundan hem de kökçük kırma işleminden etkilendiği belirlenmiştir. Tüp boyutlarındaki artı̧̧a bağlı olarak kök boğazı çapının da arttığı tespit edilmiştir. Fidan boyu için yapılan değerlendirmelerde de en büyük tüp boyutunda $(18 \times 30 \mathrm{~cm})$ en boylu fidanlar yetiştirilirken, $12 \times 25 \mathrm{~cm}$ tüp boyutunda en kısa boylu fidanlar üretilmiştir. Benzer şekilde Abera vd. (2018)'nin Acacia nilotica, Acacia tortilis, Dobera glabra ve Ziziphus spine-christi türlerinde 3 farklı tüp boyutunda $(8 \times 15 \mathrm{~cm}, 10 \times 15 \mathrm{~cm}$ ve $15 \times 15 \mathrm{~cm}$ ebatında) gerçekleştirdikleri çalışmada da en büyük tüp boyutunda $(15 \times 15 \mathrm{~cm})$ daha boylu ve kalın çaplı fidanlar üretilmiştir. Diğer taraftan üç farklı tüp boyutunda (170, 650 ve $1250 \mathrm{~cm}^{3}$ ) gübreli ve gübresiz ortamda yetiştirilen Quercus pagoda L. fidanlarının boyu, gürbüzlük belirteci, yaprak alanı ve yaprak, gövde ve kök ağırlıkları orta ve büyük tüp boyutunda küçük tüp boyutuna oranla tüp boyutu arttıkça çap artmış fakat istatistiksel fark çıkmamıştır. Gövde çapında ise tüp boyutu etkisi önemsiz bulunmuştur (Howell ve Harrington, 2004). Saçlı meşe fidanlarında kökçük kırmanın kök boğazı çapına ve fidan boyuna olumlu bir etkisi söz konusu olup, tüm tüp boyutlarında kontrol fidanlarına göre daha kalın çaplı, boylu fidanlar üretilmiştir. Benzer sonuç kökçükleri kırılan Quercus ilex L. fidanlarında da elde edilmiştir (Çalışkan, 2014). Bir yaşındaki tüplü Doğu kayını (Fagus orientalis Lipsky.) fidanlarında da kökçük koparma işleminde daha kalın çaplı fidanlar üretilirken, kökçük koparılmasının fidan boyu, gövde taze ve kuru ağırlığını etkilemediği belirlenmiştir (Çalıkoğlu vd., 2007). Aynı şekilde kasnak meşesinde kökçük kırma işlemi fidan boyu üzerinde etkisiz bulunmuştur (Tilki ve Alptekin, 2006). Genç vd. (2000) tarafından Kasnak meşesi (Quercus vulcanica Boiss.) türünde yapılan çalışma ise kökçük kırma işlemi kök boğazı çapını etkilememiştir.

Fidan gelişiminde artan tüp boyutunun ve kökçük kırmanın olumlu etkisi yan dal sayısı, gövde kuru ağırlığı, yan kök, ana kök ve toplam kök kuru ağırlığında da elde edilmiştir. Nitekim fidan kök boğazı çapı daha kalın olan ve fidan boyu daha uzun olan en büyük tüp boyutunda $(18 \times 30$ $\mathrm{cm})$ yetiştirilen fidanların yan dal sayısı, gövde ve kök kuru ağırlığı değerleri daha yüksek çıkmıştır. Gövde:kök oranı, fidanın çevresindeki kısıtlı kaynakları telafi etme ve böylece rekabette başarılı olma ve hayatta kalma yeteneğinin anahtarlarından birisidir (Mašková ve Herben, 2018). Genellikle kaliteli fidanların gövde:kök oranının tüplü fidanlarda $2 / 1$ ve altında olduğu belirtilmiştir (Haase, 2008). Çalışmamızda saçlı meşe fidanlarının gövde:kök oranı 2'in altındadır. Gövde:kök oranı ve kök ağırlığının yaşama yüzdesi ile ilişki olduğu birçok araştırmada bildirilmiştir (Thompson, 1985; Larsen vd., 1986). Kök sistemi, fidan gelişimi ve dikimden sonraki yaşama yüzdesini etkileyen önemli bir özelliktir (Haase, 2008). Bu çalışmada tüp boyutunun ana kök sayısı üzerinde önemli bir etkisi söz konusu değilken, kökçük kırma işlemi ana kök sayısını arttırmıştır. Tüm tüp boyutlarında ortalama ana kök sayısı kontrol fidanlarında 1 adet iken, kökçük kırma işlemi uygulanan fidanlarda ortalama 3 adet olarak belirlenmiştir. Kökçük kırmanın birden fazla ana kök dallanmasına neden olduğu birçok çalışmada bildirilmiştir. Örneğin, çimlenen tohumlarda radikula kesimi yapılan Siirt-Pervari orijinli ceviz (Juglans regia L.) fidanlarında ana kök sayısı kontrol fidanlarına göre yaklaşık 3 kat artmıştır (Tonguç ve Aydın 2019). Quercus ilex fidanlarında ise kökçük kırma işlemi ana kök sayısını 2.8 kat arttırmıştır (Çalışkan, 2014). Quercus garryana Dougl.ex Hook. türünde de benzer sonuçlara ulaşılmıştır (Devine vd., 2009). En büyük tüp boyutunda yan kök sayısı ve çapı $1 \mathrm{~mm}$ 'den büyük yan kök sayısı daha yüksektir. Birçok çalışmada çapı $1 \mathrm{~mm}$ 'den büyük yan kök sayısı fidan gelişiminin tahmininde yararlı bir ölçüm kriteri olduğu vurgulanmıştır. Yan kökler toplam kök yüzey alanını arttırırlar ve buda daha fazla su ve besin alımı, daha düşük dikim stresi ve dikim sonrası daha iyi yaşama yüzdesi ve gelişim ile ilgilidir (Thompson, 1991; Thompson ve Schultz 1995; Shultz ve Thompson, 1997; Gould ve Harrington, 2009).

$\mathrm{Bu}$ çalışmada İngiltere'de yapılan gürbüzlük indisi sınıflamasına göre farklı boyutlardaki polietilen tüplerde kontrol ve kökçük kırma işlemi ile yetiştirilen saçlı meşe fidanlarının tamamı gürbüzlük indisi 50'nin altında olduğu için iyi fidan sınıfında yer almıştır. Dickson kalite indeksi ise artan tüp boyutu ile artmıştır. Birçok çalışmada Dickson kalite indeksinin fidanın arazideki yaşama yüzdesi ve gelişiminin potansiyel bir gücünü yansıttığı vurgulanmıştır (Mañas vd., 2009). Dikimi takiben yavaşlayan fotosentezden kaynaklanan asimilat yetersizliği, kök karbonhidrat içeriği sayesinde önemli ölçüde giderilmektedir (Genç ve Yahyaoğlu, 2007). En büyük tüp boyutunda kök toplam karbonhidrat içeriği ve kök gelişme potansiyeli de yüksektir. Kökçük kırma işlemi ise 
köklerdeki toplam karbonhidrat içeriğini düşürürken, kök gelişme potansiyelini etkilememiştir. Kaliteli fidan, iyi bir arazi performansının göstergesi olarak kabul edilmektedir (Sharma ve Negi, 2018). Kök boğazı çapının ve fidan boyunun dikkate alındığ 1 TS 5624/Mart 1988 no'lu Yapraklı Orman Ağacı Fidanları standardına göre; en boylu ve kalın çaplı fidanların yetiştirildiği en büyük tüp boyutu ve kökçük kırma işlemindeki fidanların tamamının iskarta fidan olduğu, 2. kalite sınıfında bile olması gereken en az $30 \mathrm{~cm}$ boya fidanların ulaşamadığı görülmektedir. $\mathrm{Bu}$ durum mevcut standartta tür bazında ayrıma gidilmeden bütün meşe türleri için tek bir sınıflandırma yapılmış olması ile açıklanabilir.

Sonuç olarak; 1+0 yaşlı saçlı meşe fidanlarında tüp boyutu ve kökçük kırma işlemi fidan kalitesi üzerinde etkili bulunmuştur. Tüp boyutlarındaki artışa bağlı olarak kök boğazı çapı, fidan boyu, yan dal sayısı, gövde kuru ağırlığı, yan kök, ana kök ve toplam kök kuru ağırlığında artmış, kökçük kırma işleminin ise bu artışa olumlu katkısı olmuştur. Kökçük kırma birden fazla ana kök dallanmasına neden olurken, büyük tüp boyutu kök toplam karbonhidrat içeriğini ve yan kök sayısını arttırmıştır. Bu çalışmanın sonuçları geniş yapraklı türlerde kullanılan mevcut TS 5624/Mart 1988 no'lu Yapraklı Orman Ağacı Fidanları Standardı'nın da en azından tür bazında güncellenmesi gerekliliğini de ortaya koymaktadır. Yine kap tipi, yetiştirme ortamı gibi kök sistemini etkileyen faktörler konusunda da detaylı araştırmaların yapılmasına ihtiyaç bulunmaktadır. Fidanlık sonuçlarına göre, kalın çaplı, boylu, ağır ve yan kök sayısı yüksek $1+0$ yaşlı saçlı meşe fidanı üretimi için büyük tüp boyutu $(18 \times 30 \mathrm{~cm})$ önerilebilir. Bununla birlikte tüp boyutu ve kökçük kırmanın fidan kalitesi üzerindeki etkisi konusunda karar verirken sadece fidanlık sonuçlarına göre hareket etmek elbette yeterli olmayacaktır. Mutlaka yetişme ortamına göre bu fidanların arazideki yaşama yüzdesi ve gelişim performansları konusunda detaylı bir araştırma yapılması durumunda daha güvenilir sonuçlara ulaşılacağı göz ardı edilmemelidir.

\section{Açıklama}

$\mathrm{Bu}$ çalışma Isparta Uygulamalı Bilimler Üniversitesi Lisansüstü Eğitim Enstitüsü’nde hazırlanan yüksek lisans tezinin bir özetidir. Çalışmayı 2019-YL1-0008 No`lu Proje ile destekleyen Isparta Uygulamalı Bilimler Üniversitesi Bilimsel Araştırma Projeleri Yönetim Birimi Başkanlığı'na teşekkür ederiz.

\section{Kaynaklar}

Abera, B., Derero, A., Waktole, S., Yilmaz, G., 2018. Effect of pot size and growing media on seedling vigour of four indigenous tree species under semi-arid climatic conditions. Forests, Trees and Livelihoods, 27(1): 61-67.

Alptekin, Ü., İmal, B., 2010. Kurak ve yarıkurak alanlarda fidan üretimine genel bir bakış. III. Ulusal Karadeniz Ormancılık Kongresi, 20-22 Mayıs, Artvin, s.792-803.

Anşin, R., Özkan, Z. C., 1993. Tohumlu Bitkiler (Odunsu Taksonlar). Karadeniz Teknik Üniversitesi, Trabzon Basımevi.

Ayan, S., Gedik, F., Yer Çelik, E.N., Gülseven, O., Yılmaz, E., Akın, Ş.S., Özel, H.B., 2020. Bazı geniş yapraklı orman ağacı fidanlarının morfolojik özellikleri. Bartın Orman Fakültesi Dergisi, 22(1): 245-255.

Batan, M., Toprak, Z. F., 2000. İklim değişikliğinde etkenler ile sonuçların birbirini tetiklemesi. Dicle Üniversitesi Mühendislik Fakültesi Mühendislik Dergisi, 11(2): 759-769.
Boydak, M., Çalışkan, S., 2014. Ağaçlandırma. Ormancılığı Geliştirme ve Orman Yangınları ile Mücadele Hizmetlerini Destekleme Vakfı (Ogem-Vak), Ankara, ISBN: 978-97593943-8-7.

Chouial, M., Benamirouche, S., 2016. Effects of sowing methods on growth and root deformations of containerized cork oak (Quercus suber L.) seedlings in nursery. Ecologia Mediterranea, 42(1): 21-28.

Çalıkoğlu, M., Çalışkan, S., Yılmaz, M., Dirik, H., 2007. Çimlenmiş Doğu kayını (Fagus orientalis Lipsky) tohumlarının kökçüklerinin koparılarak ekilmesinin bazı fidan karakteristiklerine etkisi. İstanbul Üniversitesi Orman Fakültesi Dergisi, A57 (1): 17-30.

Çalışkan, S., 2014. Germination and seedling growth of holm oak (Quercus ilex L.): Effects of provenance, temperature and radicle pruning. Iforest-Biogeosciences and Forestry, 7(2): 103-109.

Devine, W.D., Harrington, C.A., Southworth, D., 2009. Improving root growth and morphology of containerized oregon white oak seedlings. Tree Planter' Notes, 53(2): 29-34.

Dubois, M., Gilles, K.A., Hamilton, J.K., Rebers, P.A., Smith, F., 1956. Colorimetric method for determination of sugar and related substances. Analytical Chemistry, 28: 350-356.

Genç, M., Yahyaoğlu, Z., 2007. Kalite sınıflamasında kullanılan özellikler ve tespiti. In: Fidan Standardizasyonu, Standart Fidan Yetiştirmenin Biyolojik ve Teknik Esasları (Eds: Yahyaoğlu, Z., Genç, M.), Süleyman Demirel Üniversitesi Yayınları, Yayın No. 75, Isparta, s:467-491.

Genç, M., Gülcü, S., Bilir, N., 2000. Kasnak meşesi (Ouercus vulcanica Boiss)'de meyve tipi-ekim şekli-fidan morfolojisi etkileşimleri. Orman Mühendisliği Dergisi, 37(8): 21-24.

Gould, P.J., Harrington, C.A., 2009. Root morphology and growth of bare-root seedlings of oregon white oak. Tree Planters Notes, 53(2): 22-28.

Grossnickle S. C., 2005. Importance of root growth in overcoming planting stress. New Forests, 30(2-3): 273-294.

Haase, D.L., 2008. Understanding forest seedlig quality: Measurements and interpretation. Tree Planters Notes, 52(2): 24-30.

Hahn, P., Hutchison, S., 1978. Root from of planted trees and their performance. Proceedings of The Root Form of Planted Trees Symposium. May 16-19, Victoria, British Columbia, pp. 235240.

Howell, K.D., Harrington, T.B., 2004. Nursery practices influence seedling morphology, field performance, and cost efficiency of containerized Cherrybark oak. Southern Journal of Applied Forestry, 28(3): 152-162.

İğci, T., Çobanoğlu, N., 2019. İklim değişikliğinin ve iklim değişikliğiyle ilgili küresel anlaşmaların çevre etiği bakımından değerlendirilmesi. Ankara Üniversitesi Çevrebilimleri Dergisi, 7(2): $130-146$.

Landis, T.D., Tinus, R.W., Mcdonald S.E., Barnett J.P., 1990. The Container Tree Nursery Manuel. Agiculture handbook 674, USDA, Forest Service

Larsen, H.S., South, D.B., Boyer, J.M., 1986. Root growth potential, seedling morphology and bud dormancy correlate with survival of loblolly pine seedlings planted in december in alabama. Tree Physiology, 1: 253-263.

Mañas, P., Castro, E., Heras, J., 2009. Quality of Maritime pine (Pinus pinaster Ait.) seedlings using waste materials as nursery growing media. New Forests, 37: 295-311.

Mašková, T., Herben, T., 2018. Root:shoot ratio in developing seedlings: how seedlings change their allocation in response to seed mass and ambient nutrient supply. Ecology And Evolution 8: 7143-7150

Mathers, H.M., Lowe, S.B., Scagel, C., Struve, D.K., Kase, L.T., 2007. Abiotic factors influencing root growth of woody nursery plants in containers. Hort Technology, 17(2): 151-162.

Nesmith, D.S., Duval, J.D., 1998. The effects of container size. Hort Technology, 8(4): 495-498. 
Schultz, R., Thompson, J., 1997. Effect of density control and undercutting on root morphology of $1+0$ bareroot hardwood seedlings: five-year field performance of root-graded stock in the central usa. New Forests 13: 301- 314.

Sharma, S., Negi, P.S., 2018. Effect of seedling height and diameter of nursery stock of ban oak on out planting survival. Journal of Tree Sciences, 37(2): 68-74.

Sutton, R. F., 1980. Root system morphogenesis. New Zealand Journal of Forestry Science, 10(1): 265-283.

Thompson, E. B., 1985. Seedling Morphological Evaluation: What You Can Tell By Looking. In Evaluating Seedling Quality: Principles, Procedures, and Predictive Abilities of Major Tests. Forest Research Laboratory, Oregon State University, Corvallis.

Thompson, J. R., 1991. Influence of root system morphology and site characteristics on development of transplanted northern red oak (Quercus rubra L.) seedlings. PhD Dissertation, Iowa State University, Ames, Iowa.
Thompson, J.R., Schultz, R.C., 1995. Root system morphology of Quercus rubra L. planting stock and 3-year field performance in Iowa. New Forests, 9(3): 225-236.

Tilki, F., Alptekin, C.U., 2006. Germination and seedling growth of Quercus vulcanica: effects of stratification, desiccation, radicle pruning, and season of sowing. New Forests, 32: 243-251.

Tonguç, F., Aydın, M., 2019. Radikula ve yerinde kök kesimi uygulamalarının Siirt-Pervari orijinli ceviz fidanlarında (Juglas regia) bazı fidan kalite özelliklerine etkisi. Iğdır Üniversitesi Fen Bilimleri Enstitüsü Dergisi, 9(3): 1683-1691.

Tüfekçi S., Gürlevik N., Polat O., Topal A., Polat S., Gültekin H. C., 2016. Yerel mikorizal türlerle aşılamanın saçlı meşe (Quercus cerris L.) fidanı gelişimine etkileri. Ormanc1lık Araştırma Dergisi, 1(3): 38-49.

Türkeș, M. T., 2020. İklim değișikliğinin tarımsal üretim ve gıda güvenliğine etkileri: Bilimsel bir değerlendirme. Ege Coğrafya Dergisi, 29(1): 125-149.

Yaltırık, F., 1984. Türkiye Meşeleri Teşhis Kılavuzu. Yenilik Basım Evi, İstanbul. 